\title{
A Comparison of Safety Factor Values for Soderberg and DIN 743 Fatigue Analyses
}

\author{
Beatriz Henriques ${ }^{1}$, Mariana Carvalho ${ }^{2}$, Sérgio M. O. Tavares ${ }^{3}$, \\ Paulo M. S. T. de Castro ${ }^{4}$
}

${ }^{1}$ Faculty of Engineering, University of Porto, Rua Dr. Roberto Frias, 4200-465 Porto, Portugal (up201606864@fe.up.pt); '2Faculty of Engineering, University of Porto, Rua Dr. Roberto Frias, 4200-465 Porto, Portugal (up201605417@fe.up.pt); ${ }^{3}$ Faculty of Engineering, University of Porto, Rua Dr. Roberto Frias, 4200-465 Porto, Portugal; Efacec Energia, 4471-907 Moreira da Maia, Portugal (sergio.tavares@fe.up.pt) ORCID 0000-0003-0054-0771; ${ }^{4}$ Faculty of Engineering, University of Porto, Rua Dr. Roberto Frias, 4200-465 Porto, Portugal (ptcastro@fe.up.pt) ORCID 0000-0003-3202-1343

\begin{abstract}
Fatigue phenomena are critical aspects of the life cycle of many components or structures. The variety of cyclic load situations led to the emergence, throughout the years, of different types of studies as high-cycle, low-cycle, and fatigue crack growth, among others. Particularly for machine elements, high-cycle fatigue situations are the more frequent, and simplified approaches taking into account the Soderberg criterion have been commonly used. Meanwhile, the German Institute for Standardization put forward a procedure for fatigue design of shafts, DIN 743, based on the use of Smith diagrams and considering separately the safety factor (SF) for static and for cyclic loads. The present paper compares Soderberg and DIN 743 approaches, focusing on SF obtained when load capacity is calculated considering equal correction factors in both methods. A set of representative situations was defined, and the comparison was carried out parametrically using Matlab software. The SF values of the Soderberg method were always found to be lower than those of DIN 743, indicating that the Soderberg method is more conservative than DIN 743.
\end{abstract}

Author Keywords. High Cycle Fatigue, ASME B106, Soderberg Criterion, DIN 743, Safety Factor.

Type: Research Article

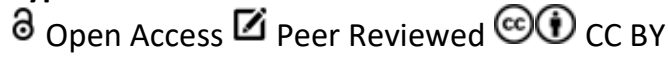

\section{Introduction}

Fatigue is a phenomenon where materials suffer damage due to cyclic loads, eventually leading to complete rupture. As a consequence, fatigue behavior must be considered during the design phase of machines and structures, for adequate estimation of safety factors and life expectancy, e.g. (Zaretsky 1987). Fatigue failures in many different fields have been investigated, e.g. (Gagg and Lewis 2009; de Castro and Fernandes 2004; Tavares et al. 2016), allowing to understand the fatigue behavior of different materials and to improve the design and reliability of new products.

The variety of cyclic load situations leading to fatigue failure led to the emergence, throughout the years, of different types of studies as high-cycle, low-cycle, and fatigue crack growth. For machine elements, in particular, high cycle fatigue situations are the most frequent, e.g. (Lee et al. 2005; Lee, Barkey, and Kang 2012; Milella 2013). The documents ASME B106 (ANSI/ASME 1985) and DIN 743 (DIN 2012) offer relatively simple procedures to address this problem. 
This article assesses two approaches for high cycle fatigue design: the ASME B106 (based on the Soderberg criterion) and DIN 743, considering diverse combinations of bending and torsional loads. High cycle fatigue studies include consideration of surface finish, size, temperature and other aspects, as discussed in detail in design of machine elements textbooks as Juvinall and Marshek (2017) or Budynas and Nisbett (2011). In the present work, for each load case considered, only the analysis methodology was varied - Soderberg or DIN 743 -, keeping everything else constant, including material properties, stress state and fatigue correction factors. For each loading condition considered, the safety factors were calculated and compared 'ceteris paribus', allowing to evaluate differences between the two design approaches considered. Although the Soderberg and DIN 743 methodologies are well known - Soderberg since the nineteen thirties (Soderberg 1933), and DIN 743 since its first draft appearance in 1998 -, a comparison as the present one was not found in the literature.

\subsection{ASME B106}

Based on Soderberg's method, ASME B106 (ANSI/ASME 1985) uses the stress ratio parameter, $R$, to describe the mean load or stress. This is defined as the ratio between the minimum $\left(\sigma_{\min }\right)$ and maximum $\left(\sigma_{\max }\right)$ stresses:

$$
R=\frac{\sigma_{\min }}{\sigma_{\max }}
$$

A fatigue load can be represented as the sum of a static load with a sinusoidal one (Figure 1).

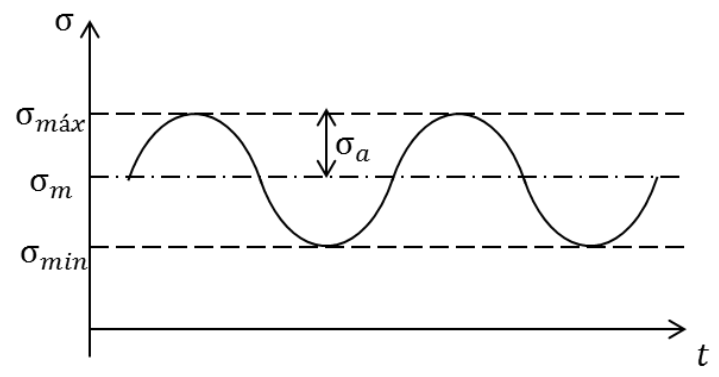

Figure 1: Cyclic normal stress

The static component is characterized by an average normal stress, $\sigma_{m}$, and the sinusoidal component by its amplitude, $\sigma_{a}$. The sum of these components is the maximum normal stress, $\sigma_{\text {max }}$. Equation (2), Equation (3) and Equation (4) show the relations between the parameters referred above.

$$
\begin{gathered}
\sigma_{m}=\frac{\sigma_{\text {max }}+\sigma_{\text {min }}}{2} \\
\sigma_{a}=\frac{\sigma_{\text {max }}-\sigma_{\text {min }}}{2} \\
\sigma_{\text {max }}=\sigma_{m}+\sigma_{a}
\end{gathered}
$$

A similar approach can be applied to shear stresses. Therefore, $\tau_{m}$ is the average shear stress, $\tau_{a}$ is the amplitude of the shear stress and $\tau_{\max }$ and $\tau_{\min }$ are the maximum and minimum shear stresses. Its relationships are established in Equation (5), Equation (6) and Equation (7).

$$
\begin{aligned}
\tau_{m} & =\frac{\tau_{\max }+\tau_{\min }}{2} \\
\tau_{a} & =\frac{\tau_{\max }-\tau_{\min }}{2}
\end{aligned}
$$




$$
\tau_{\max }=\tau_{m}+\tau_{a}
$$

Soderberg's criterion states that, for a static load, $\sigma_{m}$ should at most equal the material's yield strength $\left(\sigma_{y}\right)$ to avoid permanent strain and, for a pure cyclic load, $\sigma_{a}$ should be at most the material's fatigue strength $\left(\sigma_{f o}\right)$ under $R=-1$. Equation (8) describes this criterion, illustrated in Figure 2. Safety is guaranteed below the represented line.

$$
\sigma_{a}=\sigma_{f o}\left(1-\frac{\sigma_{m}}{\sigma_{y}}\right)
$$

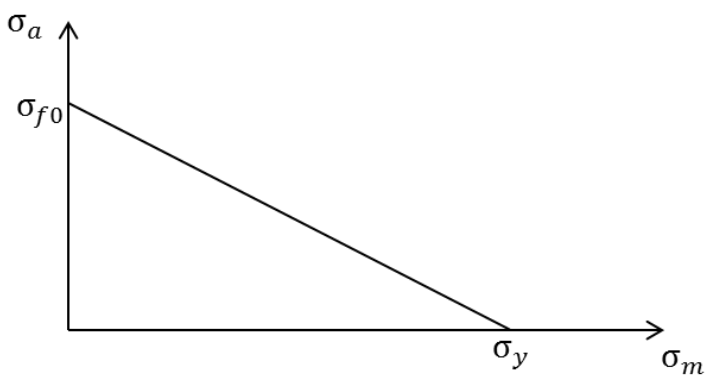

Figure 2: Soderberg's Line

Multiaxial loading situations are frequent in engineering practice. Advanced methodologies are available, as critical plane theories and others, see e.g. (Milella 2013; de Freitas 2017; Lee, Barkey, and Kang 2012). A particular case of widespread interest are transmission shafts, typically subjected to bending and torsion, where simplified methods are widely used, e.g. (Beswarick 1988; Shigley 1970; Shigley 1977). It is common to resort to parameters as equivalent static stress $\left(\sigma_{s t}{ }^{e q}\right)$ and equivalent static shear stress $\left(\tau_{s t}{ }^{e q}\right)$, defined in Equation (9) and Equation (10). In these equations, $\sigma_{y-M}$ is the flexural yield strength, $\sigma_{f o-M}$ is the fatigue strength under bending, $\tau_{y-T}$ is the torsional yield strength and $\tau_{f o-T}$ is the fatigue strength under torsion.

$$
\begin{gathered}
\sigma_{s t}{ }^{e q}=\sigma_{m}+\frac{\sigma_{y-M}}{\sigma_{f o-M}} \sigma_{a} \\
\tau_{s t}{ }^{e q}=\tau_{m}+\frac{\tau_{y-T}}{\tau_{f o-T}} \cdot \tau_{a}
\end{gathered}
$$

Using the von Mises criterion it is possible to establish Equation (11) to calculate the safety factor $(S)$ of each situation.

$$
\frac{1}{S}=\frac{\sqrt{\left(\sigma_{s t}^{e q}\right)^{2}+3 \cdot\left(\tau_{s t}^{e q}\right)^{2}}}{\sigma_{y}}
$$

\subsection{DIN 743}

Just as in the previous approach, the maximum normal $\left(\sigma_{\max -M}\right)$ and shear stresses $\left(\tau_{\max -T}\right)$ are described similarly - Equation (12) and Equation (13).

$$
\begin{gathered}
\sigma_{\text {max }-M}=\sigma_{m-M}+\sigma_{a-M} \\
\tau_{\text {max }-T}=\tau_{m-T}+\tau_{a-T}
\end{gathered}
$$

The safety factor is also established using the von Mises criterion, but in this case a static $\left(S_{s t}\right)$ and a fatigue safety coefficient $\left(S_{\text {fat }}\right)$, Equation (14) and Equation (15) are considered. For each $R$ and type of load, there is a characteristic value of the fatigue strength. 


$$
\begin{gathered}
\frac{1}{S_{s t}}=\sqrt{\left(\frac{\sigma_{\max -M}}{\sigma_{y-M}}\right)^{2}+\left(\frac{\tau_{\max -T}}{\tau_{y-T}}\right)^{2}} \\
\frac{1}{S_{f a t}}=\sqrt{\left(\frac{\sigma_{a-M}}{\sigma_{f o-M}}\right)^{2}+\left(\frac{\tau_{a-T}}{\tau_{f o-T}}\right)^{2}}
\end{gathered}
$$

The development of fundamentals of DIN 743 on load capacity of shafts and axles (as well as guidelines for the calculation of the tooth root load capacity of internal gears), was led by Heinz Linke at Dresden TU (Linke, Börner, and Heß 2016). The DIN 743 standard has been adopted for the fatigue design of shafts by KISSsoft and MESYS software, among other professional machine design software packages.

\section{Material and Methods}

The present study addresses the comparison between ASME B106 and DIN 743 focusing on the safety factors. As mentioned before, for any given load case studied, the safety factors were calculated and compared 'ceteris paribus', allowing to evaluate the differences between the two design approaches considered. The approach yielding the lowest safety factor value is picked as the most conservative. Another analysis of these two methods can be consulted in Tavares and de Castro (2017), where the correction factors where compared.

\subsection{Initial considerations and data}

The correction factors such as size and surface factors are disregarded, as they are assumed similar for both analyses considered.

The E335 steel (European Committee for Standardization 2019), commonly used for shafts, is the material considered in the study. The fatigue strength for bending and torsion are considered for $R=-1$ and $R=0$, as well as the yield strength for bending, torsion and for an axial loading $\left(\sigma_{y-N}\right)$. These properties are shown in Table 1.

$$
\sigma_{y-N}=335 \mathrm{MPa}
$$

\begin{tabular}{|c|c|c|c|}
\hline \multirow{2}{*}{$\begin{array}{c}\text { Strength } \\
\text { (MPa) }\end{array}$} & \multicolumn{2}{|c|}{ Fatigue (MPa) } & \multirow{2}{*}{$\begin{array}{c}\text { Yield } \\
\text { (MPa) }\end{array}$} \\
\cline { 2 - 3 } & $\boldsymbol{R}=-\mathbf{1}$ & $\boldsymbol{R}=\mathbf{0}$ & $\sigma_{y-M}=400$ \\
\hline Bending & $\sigma_{f o-M}=290$ & $\sigma_{f o-M}=200$ & $\tau_{y-T}=230$ \\
\hline Torsion & $\tau_{f o-T}=180$ & $\tau_{f o-T}=115$ & \\
\hline
\end{tabular}

Table 1: Mechanical properties of steel E335 (Wittel et al. 2013)

Moreover, the range of values considered for the bending $(M)$ and torsional $(T)$ stresses are defined:

$$
\begin{gathered}
M \in[0 ; 250] \mathrm{MPa} \\
T \in[0 ; 250] \mathrm{MPa}
\end{gathered}
$$

\subsection{Definition of types of loading considered}

For the comparison between the safety factors of the Soderberg's and DIN 743 fatigue analyses, 7 types of loading are considered, bearing in mind that these are a combination of bending and torsional loadings and that 2 values for $R$ are chosen (Table 2):

a) Alternating bending stress with $R=-1(M)$ and constant torsional stress (T);

b) Alternating bending $(M)$ and torsional stress $(T)$ with $R=-1$;

c) Constant bending stress $(M)$ and alternating torsional stress $(T)$ with $R=-1$;

d) Alternating bending stress $(M)$ with $R=-1$; 
e) Alternating torsional stress $(T)$ with $R=-1$;

f) Pulsating bending stress $(M)$ with $R=0$;

g) Pulsating torsional stress $(T)$ with $R=0$.

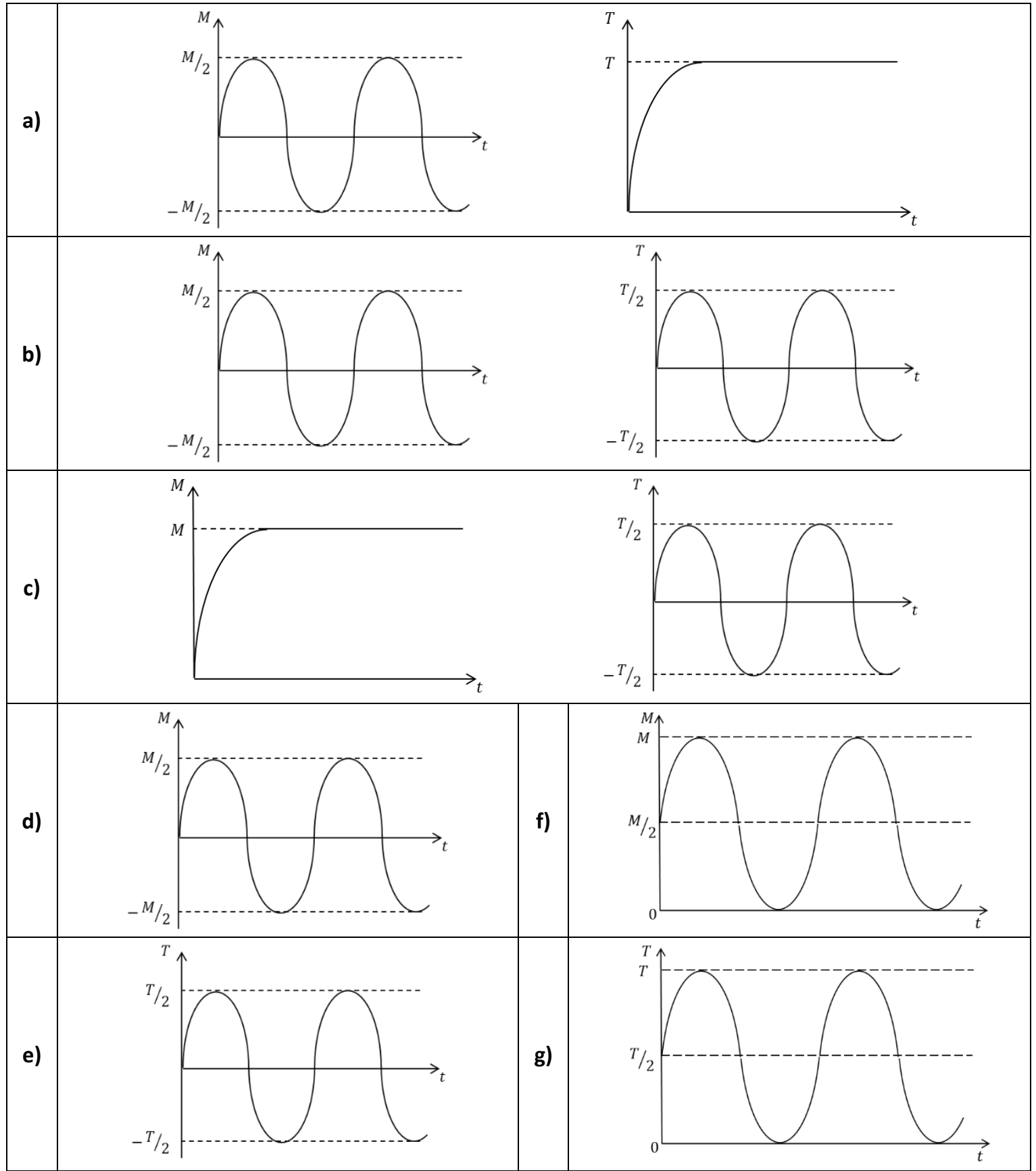

Table 2: Types of loadings considered

Recalling the Soderberg method, the values of the equivalent static stress and equivalent static shear stress need to be written as dependent of the bending $(M)$ and torsional $(T)$ stresses. For the DIN 743 standard, it is required to establish the maximum normal and shear stresses along with their amplitudes for each specific loading - Table 3. 


\begin{tabular}{|c|c|c|c|c|c|c|}
\hline \multirow{2}{*}{ Loading } & \multicolumn{2}{|c|}{ Soderberg's method } & \multicolumn{4}{|c|}{ DIN 743 } \\
\cline { 2 - 7 } & $\boldsymbol{\sigma}_{\boldsymbol{s t}}{ }^{\boldsymbol{e q}}$ & $\boldsymbol{\tau}_{\boldsymbol{s t}}{ }^{\boldsymbol{e q}}$ & $\boldsymbol{\sigma}_{\boldsymbol{m a x}-\boldsymbol{M}}$ & $\boldsymbol{\sigma}_{\boldsymbol{a}-\boldsymbol{M}}$ & $\boldsymbol{\tau}_{\boldsymbol{m a x}-\boldsymbol{T}}$ & $\boldsymbol{\tau}_{\boldsymbol{a}-\boldsymbol{T}}$ \\
\hline a) & $\frac{400}{290} \cdot \frac{M}{2}$ & $T$ & $\frac{M}{2}$ & $\frac{M}{2}$ & $T$ & 0 \\
\hline b) & $\frac{400}{290} \cdot \frac{M}{2}$ & $\frac{230}{180} \cdot \frac{T}{2}$ & $\frac{M}{2}$ & $\frac{M}{2}$ & $\frac{T}{2}$ & $\frac{T}{2}$ \\
\hline c) & $M$ & $\frac{230}{180} \cdot \frac{T}{2}$ & $M$ & 0 & $\frac{T}{2}$ & $\frac{T}{2}$ \\
\hline d) & $\frac{400}{290} \cdot \frac{M}{2}$ & 0 & $\frac{M}{2}$ & $\frac{M}{2}$ & 0 & 0 \\
\hline e) & 0 & $\frac{230}{180} \cdot \frac{T}{2}$ & 0 & 0 & $\frac{T}{2}$ & $\frac{T}{2}$ \\
\hline f) & $\frac{M}{2}+\frac{400}{290} \cdot \frac{M}{2}$ & 0 & $M$ & $\frac{M}{2}$ & 0 & 0 \\
\hline g) & 0 & $\frac{T}{2}+\frac{230}{180} \cdot \frac{T}{2}$ & 0 & 0 & $T$ & $\frac{T}{2}$ \\
\hline
\end{tabular}

Table 3: Data for Soderberg's method and DIN 743, per loading case

Finally, the expressions for the safety factors can be reached - Table 4 - and a parametrical comparison can be performed using the software MATLAB.

\begin{tabular}{|c|c|c|c|}
\hline \multirow{2}{*}{ Loading } & Soderberg's Method & \multicolumn{2}{|c|}{ DIN 743 } \\
\cline { 2 - 4 } & $\mathbf{1} / \boldsymbol{S}$ & $\sqrt{\boldsymbol{S}_{\text {st }}}$ & $\mathbf{1} / \boldsymbol{s}_{\text {fat }}$ \\
\hline a) & $\frac{\sqrt{\left(\frac{400 M}{580}\right)^{2}+3 \cdot(T)^{2}}}{335}$ & $\sqrt{\left(\frac{M}{800}\right)^{2}+\left(\frac{T}{230}\right)^{2}}$ & $\sqrt{\left(\frac{M}{580}\right)^{2}}$ \\
\hline b) & $\frac{\sqrt{\left(\frac{400 M}{580}\right)^{2}+3 \cdot\left(\frac{230 T}{360}\right)^{2}}}{335}$ & $\sqrt{\left(\frac{M}{800}\right)^{2}+\left(\frac{T}{460}\right)^{2}}$ & $\sqrt{\left(\frac{M}{580}\right)^{2}+\left(\frac{T}{360}\right)^{2}}$ \\
\hline c) & $\frac{\sqrt{(M)^{2}+3 \cdot\left(\frac{230 T}{360}\right)^{2}}}{335}$ & $\sqrt{\left(\frac{M}{400}\right)^{2}+\left(\frac{T}{460}\right)^{2}}$ & $\sqrt{\left(\frac{T}{360}\right)^{2}}$ \\
\hline d) & $\frac{\sqrt{\left(\frac{400 M}{580}\right)^{2}+3 \cdot(0)^{2}}}{335}$ & $\sqrt{\left(\frac{M}{800}\right)^{2}}$ & $\sqrt{\left(\frac{M}{580}\right)^{2}}$ \\
\hline e) & $\frac{\sqrt{(0)^{2}+3 \cdot\left(\frac{230 T}{360}\right)^{2}}}{335}$ & $\sqrt{\left(\frac{T}{460}\right)^{2}}$ & $\sqrt{\left(\frac{T}{360}\right)^{2}}$ \\
\hline f) & $\frac{\sqrt{\left(\frac{M}{2}+\frac{400 M}{580}\right)^{2}+3 \cdot(0)^{2}}}{335}$ & $\sqrt{\left(\frac{M}{400}\right)^{2}}$ & $\sqrt{\left(\frac{M}{400}\right)^{2}}$ \\
\hline g) & $\frac{\sqrt{(0)^{2}+3 \cdot\left(\frac{T}{2}+\frac{230 T}{360}\right)^{2}}}{335}$ & $\sqrt{\left(\frac{T}{230}\right)^{2}}$ & $\sqrt{\left(\frac{T}{230}\right)^{2}}$ \\
\hline
\end{tabular}

Table 4: Safety factors for Soderberg's method and DIN 743, per loading case

\section{Results and Discussion}

Using a script in MATLAB, plots were drawn where the safety factors are made dependent on bending $(M)$ and torsional $(T)$ stresses. Figures $3-9$ presents this comparison, where $S$ is safety factor of Soderberg's method, $S_{s t}$ is the static safety factor and $S_{f a t}$ is the fatigue safety factor. 


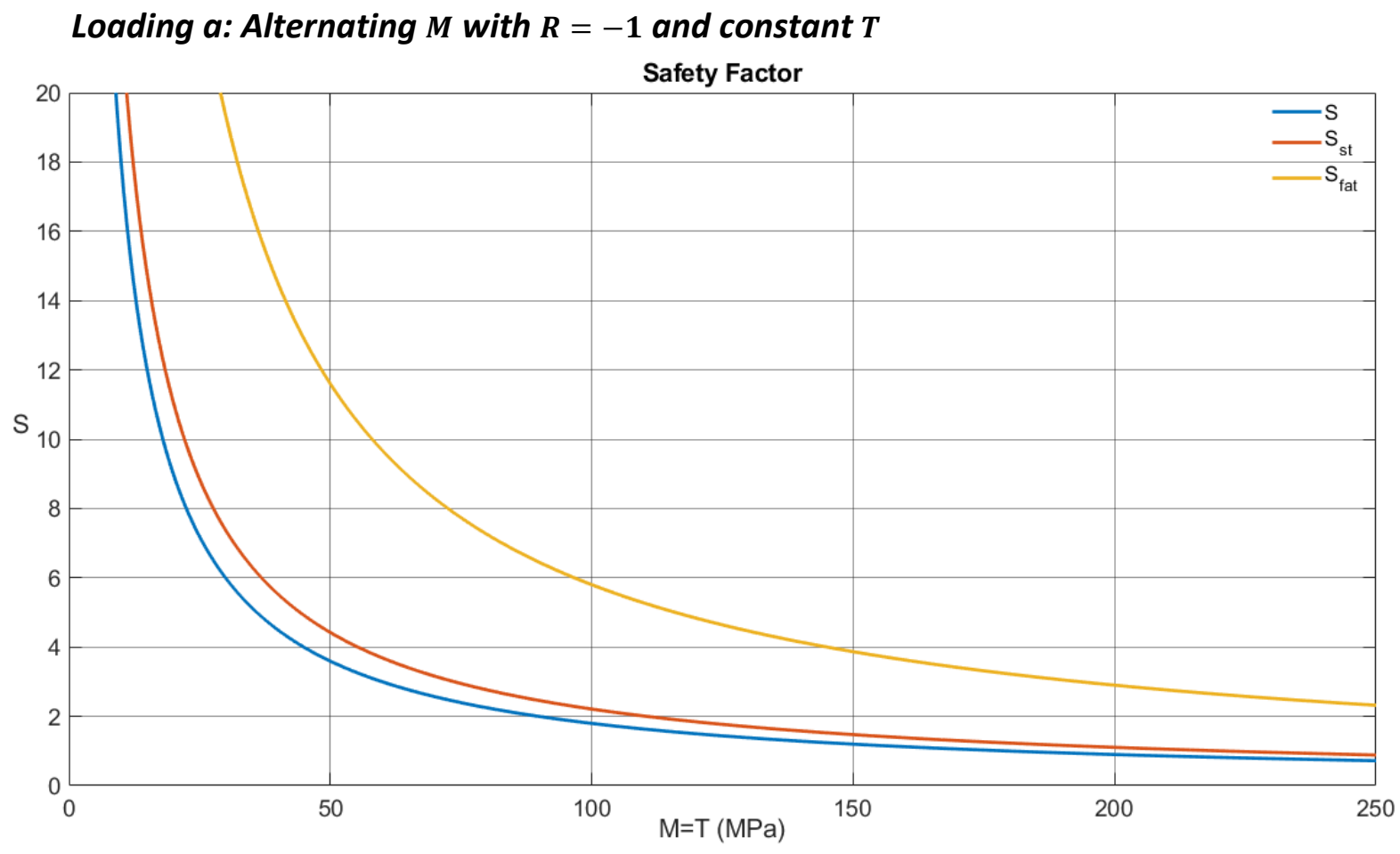

Figure 3: Safety factors considering alternating $M$ with $R=-1$ and constant $T$

In Figure 3 it is noticed that the ratios $S_{f a t} / S$ and $S_{s t} / S$ are constant and independent of the level of stress considered.

Loading b: Alternating $M$ and $T$ with $R=-1$

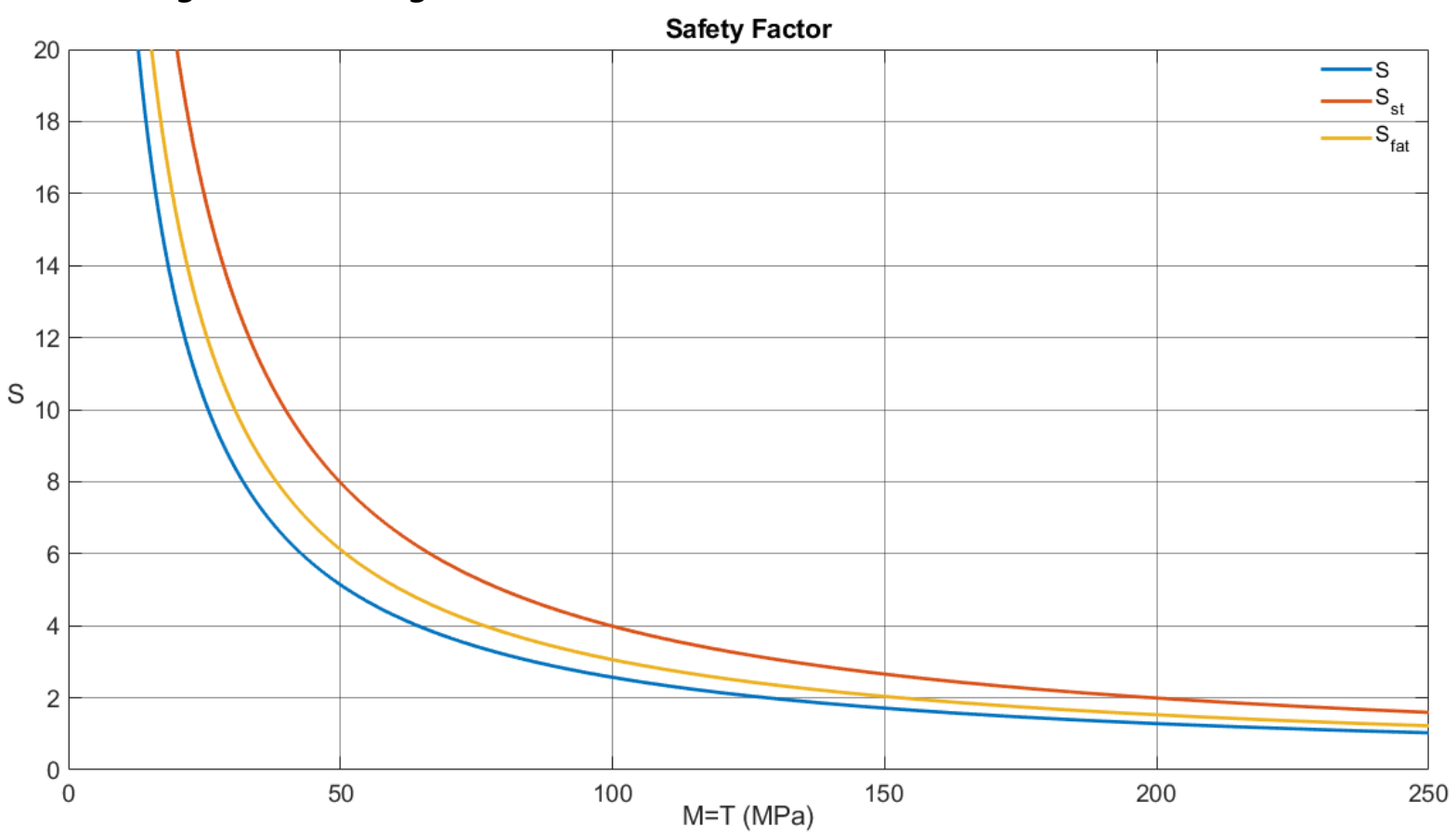

Figure 4: Safety factors considering alternating $M$ and $T$ with $R=-1$ 
Loading c: Constant $M$ and Alternating $T$ with $R=-1$

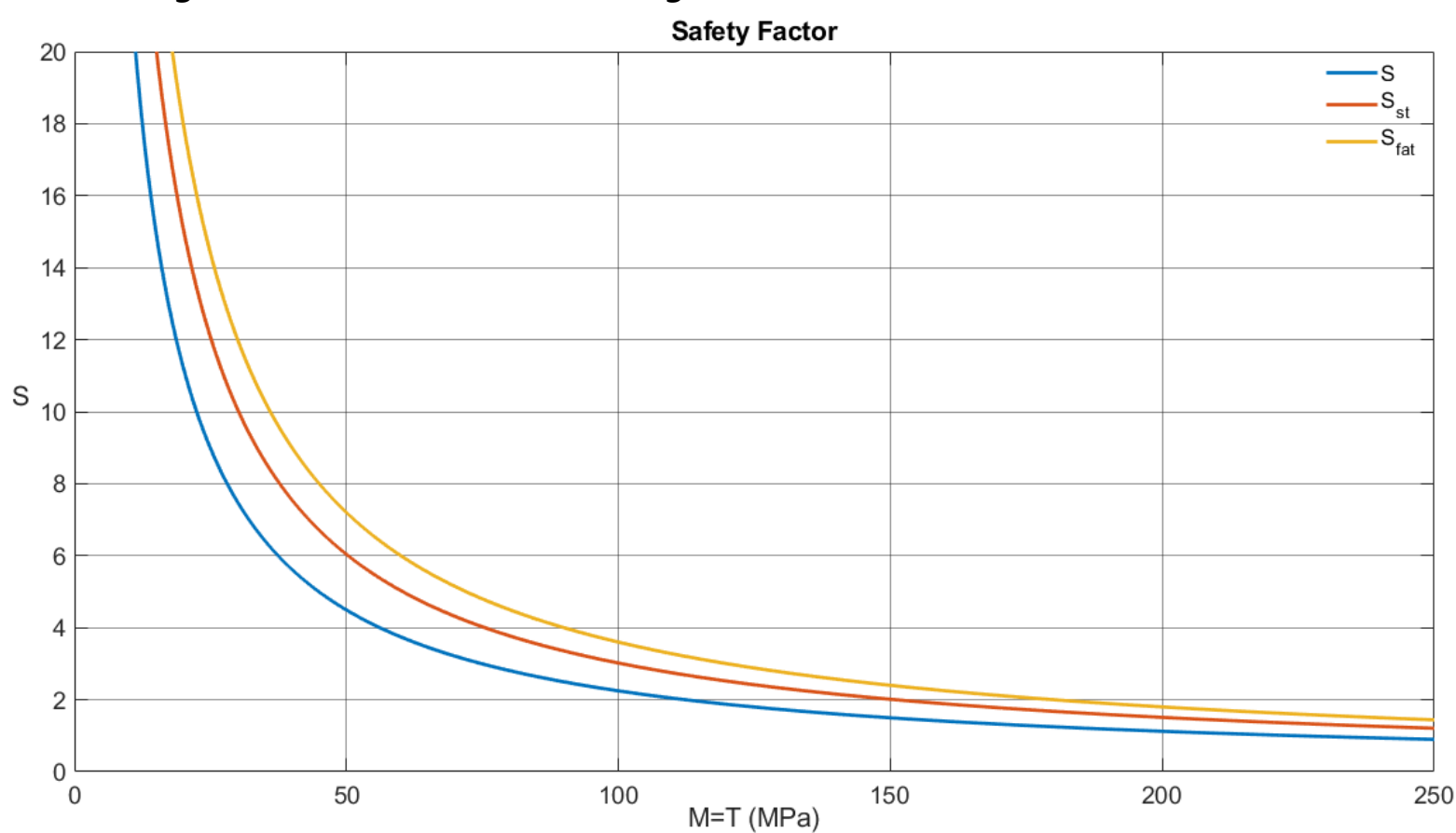

Figure 5: Safety factors considering constant $M$ and alternating $T$ with $R=-1$

Loading d: Alternating $M$ with $R=-1$

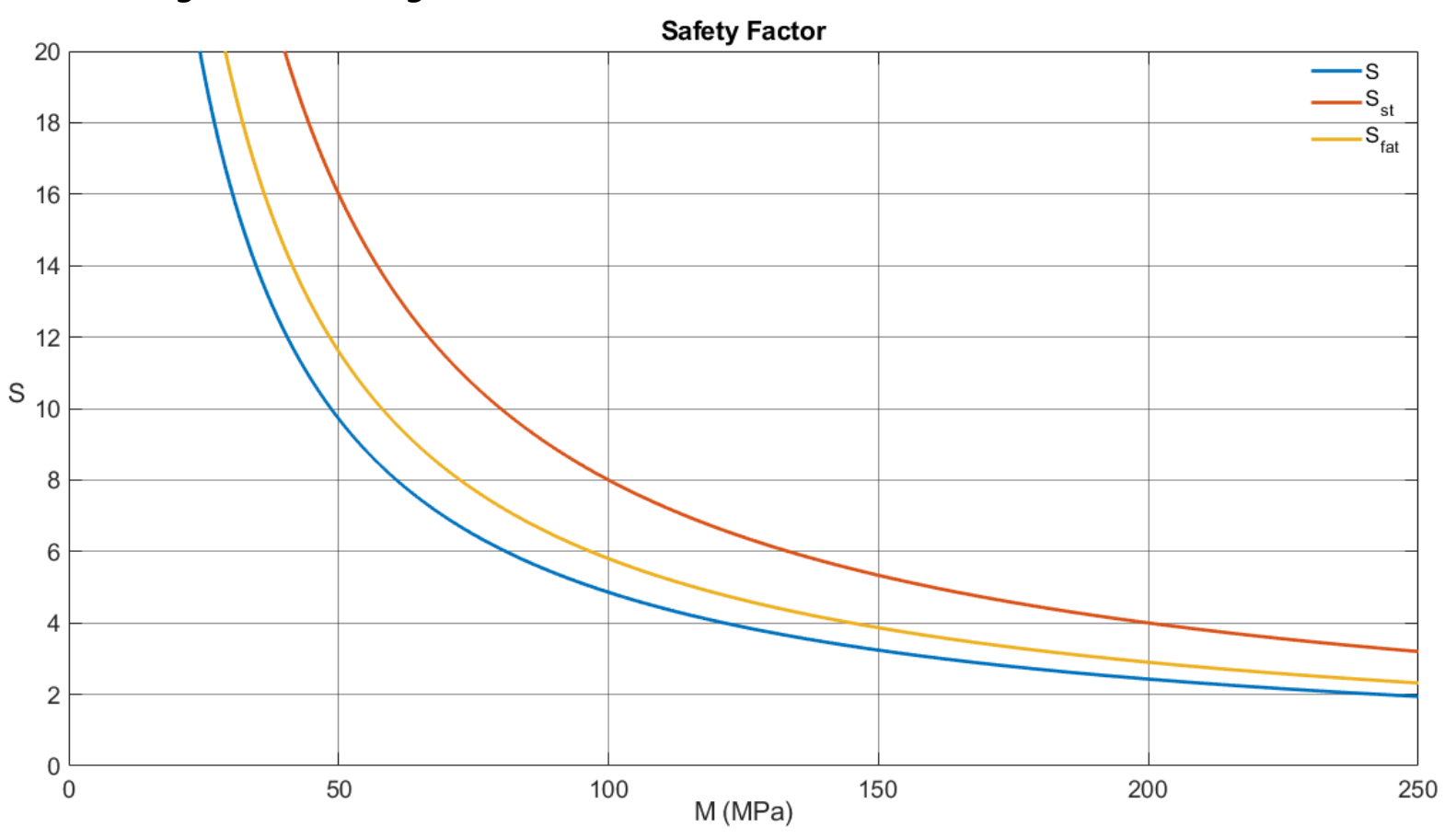

Figure 6: Safety factors considering alternating $M$ with $R=-1$ 
Loading e: Alternating $T$ with $R=-1$

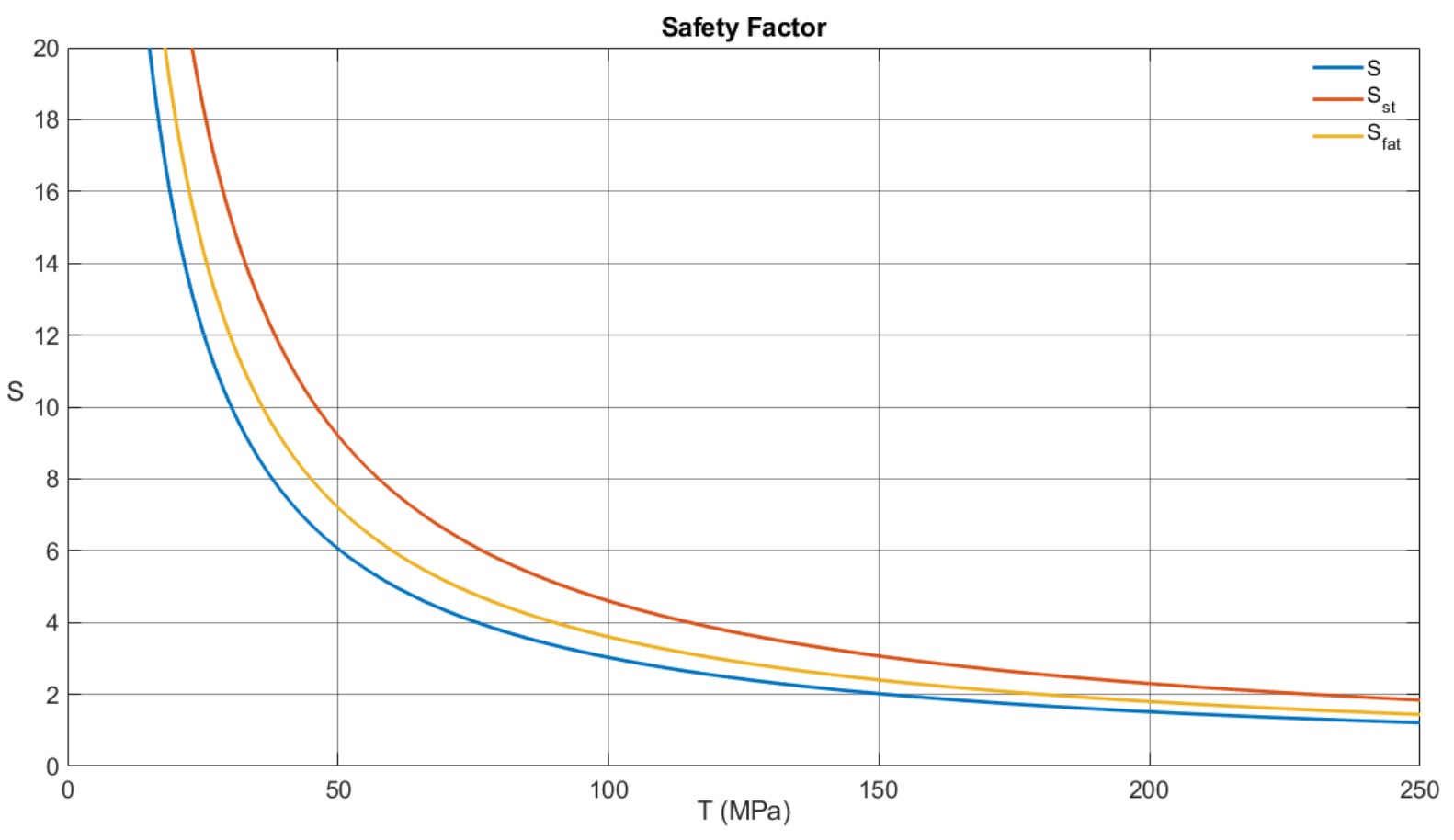

Figure 7: Safety factors considering alternating $T$ with $R=-1$

Loading f: Pulsating $M$ with $R=0$

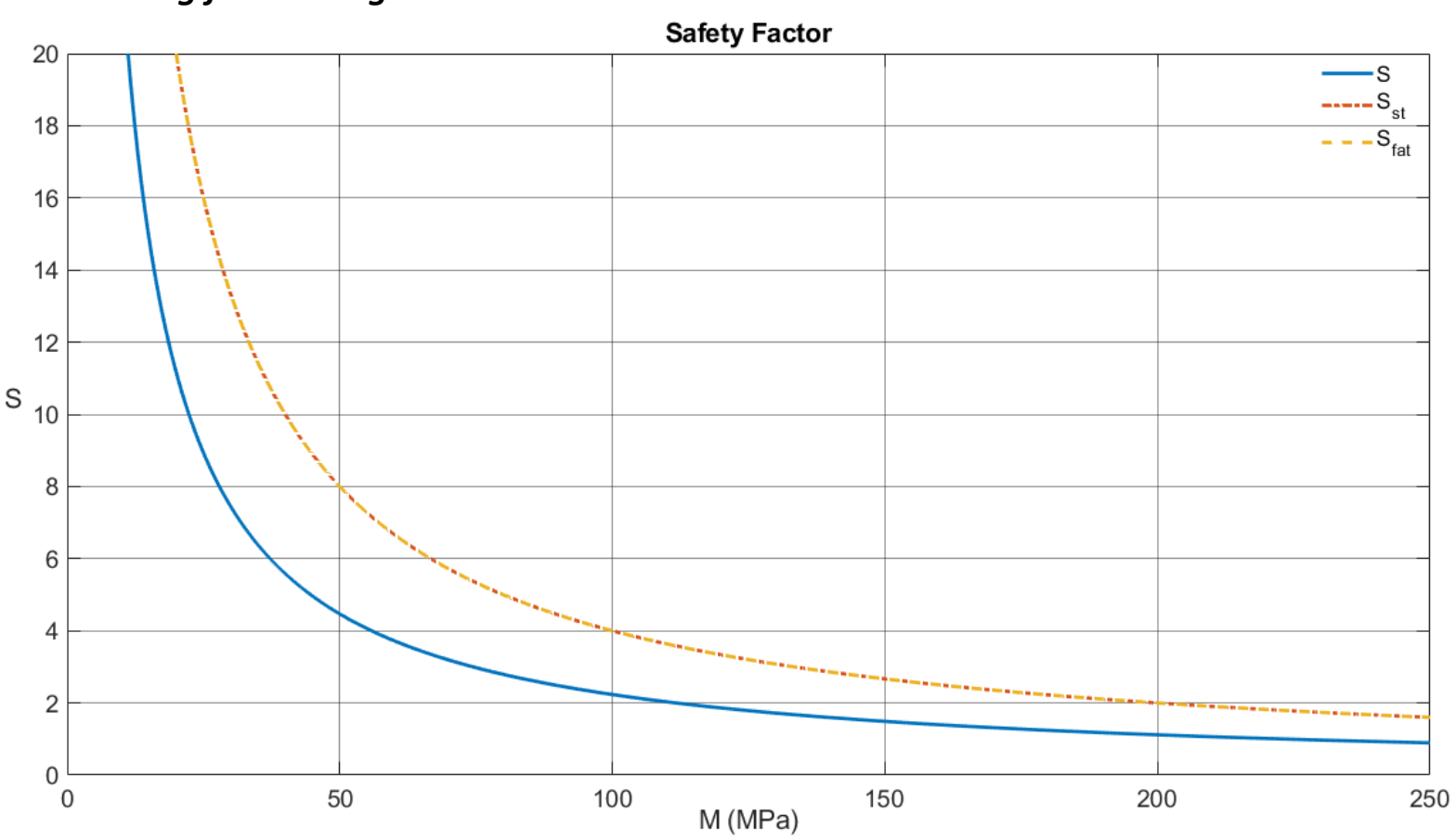

Figure 8: Safety factors considering pulsating $M$ with $R=0$ 
Loading g: Pulsating T with $R=0$

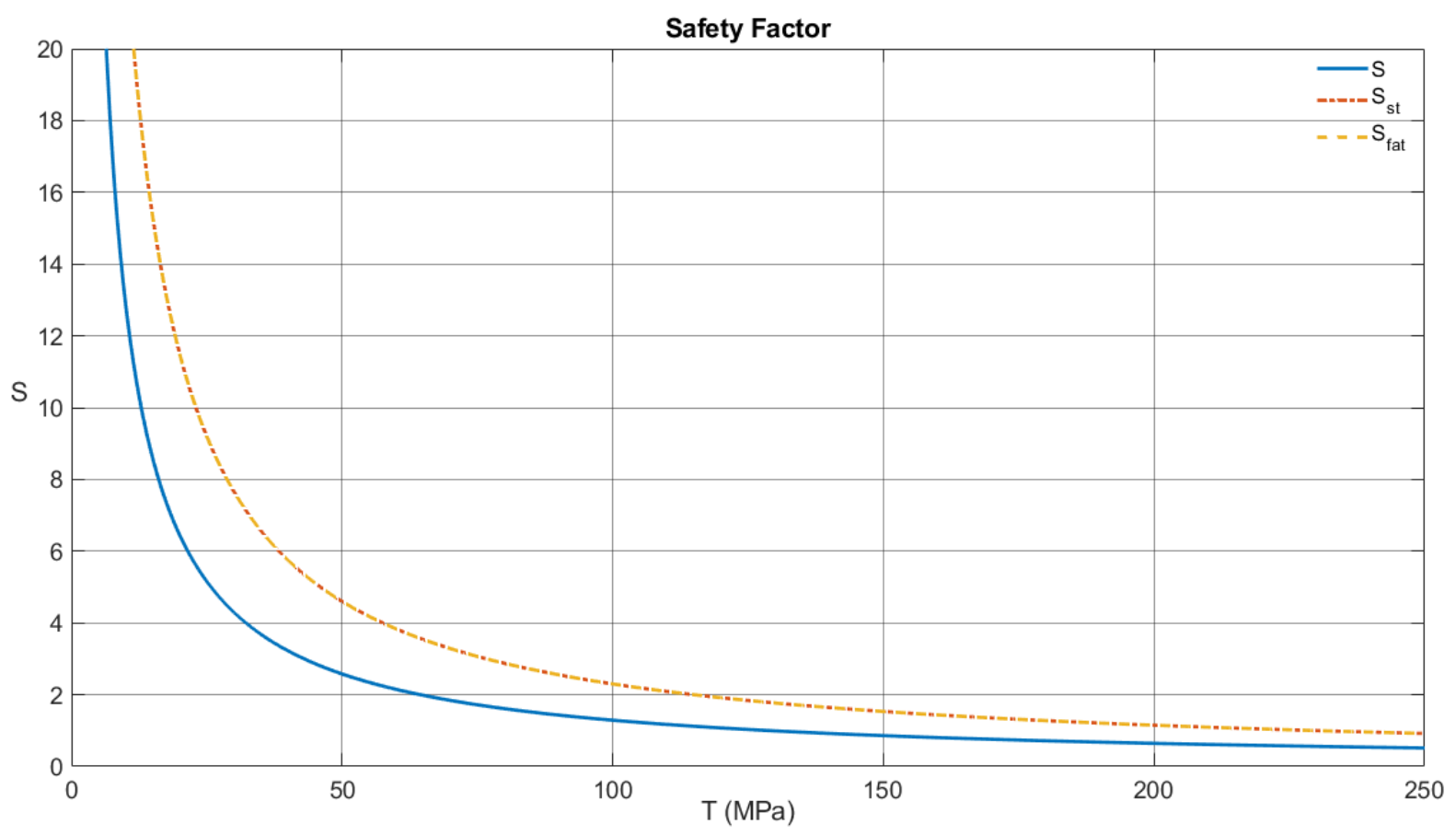

Figure 9: Safety factors considering pulsating $T$ with $R=0$

The constancy of the ratios $S_{f a t} / S$ and $S_{s t} / S$, already noticed in Figure 3, is also observed in all other load cases considered (Figures 4-9), although the values of the ratios vary with load case considered.

It is well known that Soderberg is a conservative approach to high cycle fatigue; however, given the rather different formulation of DIN 743, its comparison with DIN 743 is not direct. Within the sample of load cases considered in this work, it can be observed that the safety factor of the Soderberg method is always more conservative, as for all studied cases it is lower than for DIN 743 standard.

While using DIN 743, the load cases studied showed that in some situations the lower SF is the static one (Figure 3 and Figure 5), whereas in others the reverse is true. Of course, when using DIN 743 the lower value among $S_{f a t}$ and $S_{s t}$ should be considered.

Although the number of load cases considered is limited, it can be stated that in general the design of shafts under fatigue bending stress based on DIN 743 can result in lower diameters for the same safety factor.

In addition it should be noticed that DIN 743 recommends a minimum safety factor of 1.2 whereas, with Soderberg's method, a safety factor between 1.25 and 4 is proposed (Childs 2004), which may result in further significant differences between the two approaches.

\section{Conclusions}

A systematic comparison between the safety factor values for different loading situations using two methods of high cycle fatigue design (Soderberg and DIN 743 approaches) was presented and discussed.

The results shown that the Soderberg method is more conservative than DIN 743 as for any given case it presents lower safety factors.

\section{References}

ANSI/ASME. 1985. Standard for design of transmission shafting. ASME B106.1M. American Society of Mechanical Engineers. 
Beswarick, W. J. 1988. Component design: Shaft with fluctuating loads - Engineering Design Procedural Guide. SEED.

Budynas, R. G., and K. J. Nisbett. 2011. Shigley's mechanical engineering design. $9^{\text {th }}$ ed. McGraw-Hill.

Childs, P. R. N. 2004. Mechanical design. Elsevier Butterworth-Heinemann.

de Castro, P. M. S. T., and A. A. Fernandes. 2004. "Methodologies for failure analysis: A critical survey". Materials \& Design 25, no. 2: 117-23. https://doi.org/10.1016/j.matdes.2003.09.020.

de Freitas, M. 2017. "Multiaxial fatigue: From materials testing to life prediction". Theoretical and Applied Fracture Mechanics 360-72. https://doi.org/10.1016/j.tafmec.2017.05.008.

DIN. 2012. Calculation of load capacity of shafts and axles. DIN 743. German Institute for Standardization.

European Committee for Standardization. 2019. Hot rolled products of structural steels. Technical delivery conditions for non-alloy structural steels. European Standard EN 100252. CEN - European Committee for Standardization.

Gagg, C. R., and P. R. Lewis. 2009. "In-service fatigue failure of engineered products and structures - Case study review". Engineering Failure Analysis 16, no. 6: 1775-93. https://doi.org/10.1016/j.engfailanal.2008.08.008.

Juvinall, R. C., and K. M. Marshek. 2017. Fundamentals of machine component design. $6^{\text {th }}$ ed. Wiley.

Lee, Y.-L., J. Pan, R. Hathaway, and M. Barkey. 2005. Fatigue testing and analysis (Theory and practice). Elsevier Butterworth-Heinemann.

Lee, Y.-L., M. Barkey, and H.-T. Kang. 2012. Metal fatigue analysis handbook - Practical problem-solving techniques for computer-aided engineering. Elsevier ButterworthHeinemann.

Linke, H., J. Börner, and R. Heß. 2016. Cylindrical gears: Calculation-Materials-Manufacturing. HANSER.

Milella, P. P. 2013. Fatigue and corrosion in metals. Springer-Verlag Italia.

Shigley, J. E. 1970. El proyecto en Ingeniería Mecánica. Ediciones del Castillo.

Shigley. J. E. 1977. Mechanical engineering design. $3^{\text {rd }}$ ed. McGraw-Hill Kogakusha.

Soderberg, C. R. 1933. "Working stresses". Trans. ASME 55 no. 16: 131-44.

Tavares, S. M. O., and P. M. S. T. de Castro. 2017. "A comparison of methodologies for fatigue analysis of shafts: DIN 743 vs. approaches based on Soderberg criterion". Ciência \& Tecnologia Dos Materiais 29, no. 1: E76-E81. https://doi.org/10.1016/j.ctmat.2016.06.014.

Tavares, S. M. O., N. Viriato, M. Vaz, and P. M. S. T. de Castro. 2016. "Failure analysis of the rod of a hydraulic cylinder". Procedia Structural Integrity 1: 173-80. https://doi.org/10.1016/j.prostr.2016.02.024.

Wittel, H., D. Muhs, D. Jannasch, and J. Voßiek. 2013. Roloff/Matek Maschinenelemente: Normung, Berechnung, Gestaltung. $21^{\text {st }}$ ed. Springer.

Zaretsky, E. V. 1987. "Fatigue criterion to system design, life, and reliability". Journal of Propulsion and Power 3 no. 1: 76-83. https://doi.org/10.2514/3.22955. 